\title{
Iconografías feministas. Prácticas visuales y activismo político*
}

\author{
Florencia Laura Rovetto** \\ Mariaángeles Camusso***
}

\section{Resumen}

En este trabajo problematizamos los modos de representación y autorepresentación visual de las mujeres en el actual proceso de expansión de las luchas feministas. Nuestro análisis se centra en imágenes de mujeres que circulan por Internet $y$, en especial, en la plataforma infocomunicacional de Facebook. En los distintos acercamientos al campo observado hemos caracterizado recurrencias y disrupciones en las modalidades iconográficas que constituyen los discursos políticos, militante y ciudadano sobre y desde las mujeres. A su vez, hemos puesto en conexión tales iconografías con las luchas feministas que irrumpen en el espacio público a partir de las grandes movilizaciones de mujeres que desafían las representaciones sociales y ponen en circulación discursos contrahegemónicos, nuevas formas de acción y performance estético-políticas. Concluimos que el repertorio iconográfico analizado corre los límites de lo decible y la audible por parte del movimiento feministas contemporáneo, evidencia su voluntad de contagio y transformación, así como el carácter situado de una mirada ético-política que altera los estereotipos dominantes en el imaginario social, hasta ahora, disponible.

Palabras clave: Ciberactivismo Feminista, \#NiUnaMenos, \#VivasNosQueremos, Redes Sociales.

* Recibido el 21 de agosto de 2017, aceptado el 20 de mayo de 2020.

** Investigadora CONICET, Docente Universidad Nacional de Entre Ríos, Universidad Nacional de Rosario, Rosario, Argentina. florencia.rovetto@gmail.com / https://orcid.org/0000-0002-8900-5363.

*** Docente e Investigadora de Universidad Nacional de Rosario y Universidad Abierta Interamericana, Rosario, Argentina. mariangeles.camusso@gmail.com / https://orcid.org/0000-0002-2753-9060 
Feminist Iconographies. Visual Practices and Political Activism

\begin{abstract}
In this paper we discuss modes of visual representation and selfrepresentation of women in the current expansion of feminist struggles. Our analysis focuses on images of women that circulate on the internet and, especially on the Facebook infocommunication platform. In the different approaches to the observed field we have characterized recurrences and disruptions in the iconographic modalities that constitute political, militant and citizen discourses about and from women. We have also connected these iconographies with feminist struggles that erupted in public spaces with the large mobilizations of women that have challenged social representations and circulated counterhegemonic discourses and new forms of aesthetic and political action and performance. We conclude that the iconographic repertoire analyzed reaches the limits of what is said and heard by the contemporary feminist movement, revealing its will to spread and transform, as well as the situated character of an ethical-political view that alters the dominant stereotypes found until now in the social imaginary.
\end{abstract}

Keywords: Feminist Cyber-activism, \#NiUnaMenos, \#VivasNosQueremos, Social Networks. 


\section{Introducción en contexto y metodología de trabajo}

A Este trabajo se desprende de los estudios realizados en el marco del Centro de Investigaciones en Mediatizaciones (CIM) y del Centro de Investigaciones Feministas y Estudios de Género (CIFEG) de la Facultad de Ciencia Política y RR. II. (Universidad Nacional de Rosario-Argentina) $)^{1}$, centrados en analizar los modos en que las representaciones visuales en las redes emergen como "huellas" ${ }^{2}$ de las tensiones que configuran los imaginarios sociales en determinados momentos históricos.

Desde el año 2014 hemos abordado el universo de las redes sociales como espacio de enunciación y producción de elementos icónicos que construyen al sujeto mujeres en tanto entidad política, ciudadana o consumidora. En anteriores acercamientos al campo hemos podido determinar la reiteración de un sentido común visual hegemónico (Caggiano, 2013) que se reproduce a través de recursos estéticos tradicionalmente asociados a la "feminidad", mediante la recurrencia de elementos iconográficos estereotipados (flores acuareladas, colores pastel y fondos planos; vientres embarazados, labios carnosos, ojos grandes, cabellos largos; retratos infantilizados; proliferación de corazones u otros íconos relacionados a la maternidad y la afectividad). Todas estas formas, típicas de las representaciones de mujeres en las páginas comerciales, también pregnaban los perfiles de organizaciones feministas y de los espacios institucionales de gobierno con alto grado de imbricación en políticas de igualdad de género.

Sin embargo, en los últimos dos años hemos detectado alteraciones significativas en esta tendencia hegemónica, con la irrupción de repertorios iconográficos discordantes y cada vez más masivos -en términos productivos y de circulación- que ponen en

\footnotetext{
1 Algunos resultados de estas indagaciones fueron publicados en Cuadernos del CIM (Rovetto y Camusso, 2014, 2015 y 2017).

2 Utilizamos el concepto huella en el sentido veroniano del término: "Todo análisis del sentido descansa sobre la hipótesis según la cual el sistema productivo deja huellas en los productos y que el primero puede ser (fragmentariamente) reconstruido a partir de una manipulación de los segundos" (Verón, 1987:124).
} 
escena formas de "desobediencia estética" (Bachelard, 1964) y prácticas activistas articuladas con las históricas luchas feministas. Estos repertorios no son uniformes ni homogéneo, tal como veremos más adelante, pero pueden ser interpretados como modalidades estético-políticas y performáticas ${ }^{3}$ que irrumpen el mapa de las mediatizaciones actuales, corriendo los límites de lo visible y lo audible en determinado momento histórico, instalando discursos contrahegemónicos en y más allá de las redes.

En esta ocasión nos centramos en el análisis de las transformaciones estético-políticas registradas en la producción de iconografías feministas circulantes en Facebook (en adelante, FB), durante las sucesivas convocatorias del colectivo $\mathrm{Ni}$ Una Menos (en adelante, \#NUM). Entendemos que el relevamiento y análisis de estas iconografías informan sobre los cambios operados en los "modos de hacer y de decir" de un movimiento político heterogéneo, amplio, masivo y, cada vez, más organizado.

A modo de hipótesis de trabajo se sostiene que en la producción iconográfica y en el uso de las tecnologías infocomunicacionales se puede observar la reconfiguración progresiva de las prácticas y discursos activistas que, a través de nuevas formas creativas, sutiles y certeras, se orientan a subvertir las representaciones mediática de las violencias sexistas, ancladas en la repetición de imaginarios victimizantes.

Nos valemos del término iconografía para identificar un corpus de análisis que combina elementos discursivos diversos: imágenes fijas o en movimiento, ilustraciones, fotografías, montajes, textos. Pero, a su vez, con esta categoría procuramos articular una mirada genealógica sobre los modos de producción visual en el espacio público, con el análisis de materialidades significantes (de Lauretis, 1992:1984) que se replican, solapan,

${ }^{3}$ La propuesta metodológica de Taylor y Fuentes (2011) aplicada a las performances contempla su doble valía: archivo y repertorio. En este trabajo utilizamos el término performances en ambos sentidos, indistintamente, ya que las iconografías analizadas pueden considerarse como archivos disponibles para su reproducción en distintos soportes y como repertorio "vivo", cambiante e inacabado que se configura gracias a la dinámica propia de las redes virtuales. 
contestan, yuxtaponen y proyectan en las redes y más allá de ellas.

El tratamiento de los datos implicó, pues, desarrollar una metodología de observación con el fin de relevar constantes y disrupciones en las construcciones iconográficas, entendiendo que un análisis de corte semiológico requiere "identificar y describir todas las operaciones que, en el discurso soporte determinan la posición del enunciador y del destinatario" (Verón, 1987), pero reconociendo que la discursividad de las redes sociales implica un proceso de frecuente y veloz intercambio entre ambas posiciones.

Dada la multiplicidad de imágenes analizadas y la diversidad de recursos perceptibles en sus configuraciones, intentamos ordenar este proceso de observación, atendiendo a las operaciones retóricas (adjunción, supresión, sustitución y permutación) puestas en juego y las relaciones intertextuales (intratexto, extratexto, interdiscurso, metatexto, architexto, paratexto) que propician (Calabrese, 1999). Ambos niveles de análisis posibilitan discurrir sobre las modalidades de configuración visual que dan cuenta de la irrupción masiva de las discursividades feministas en la esfera pública contemporánea.

A continuación, presentamos sucintamente la cronología de acontecimientos que configuran el escenario de emergencia de las producciones iconográficas analizadas en el tercer apartado, donde exponemos algunos ejemplos relevados de la página de FB \#NUM, sistematizamos sus principales características y observamos sus transformaciones en un tiempo relativamente corto, pero intenso, que abarca apenas dos años.

\section{Repertorio de acontecimientos}

Las crónicas periodísticas diarias de femicidios durante los primeros meses de 2015, contribuyeron con la emergencia de la producción iconográfica analizada. Con ellas se multiplican exponencialmente las estrategias por el reconocimiento de demandas y reivindicaciones históricas del movimiento feminista que ganaron terreno en las redes, los medios masivos, los 
escenarios tradicionales de la política $y$, fundamentalmente, en las calles.

En ese marco, el colectivo \#NUM se constituye como actor político integrado por "periodistas, artistas, investigadoras y activistas" . Al tiempo que emerge su identidad en $\mathrm{FB}$, el 26 de marzo de 2015, convoca a una maratón de lectura contra los femicidios donde participan escritores, periodistas y artistas en el espacio público de la Plaza de la Biblioteca Nacional, en la ciudad de Buenos Aires.

Las iniciativas emprendidas para visibilizar el problema de las violencias contra las mujeres se expanden y multiplican en poco tiempo. El 10 de mayo del mismo año, tras la noticia del hallazgo sin vida de Chiara $\mathrm{Paez}^{5}$, se inicia una reacción en cadena que comienza a circular por las redes sociales (principalmente, Facebook y Twiter) y, rápidamente, ocupa todo el arco mediático ${ }^{6}$.

En las redes se puede ubicar el origen y la visibilidad viral de la convocatoria a la que sería la primera y más masiva movilización nacional contra las violencias sexistas. Con una frase

${ }^{4}$ En la página oficial de \#NUM se presentan de ese modo y consignas los nombres propios de las integrantes que conforman el colectivo: Marta Dillon, Agustina Paz Frontera, Florencia Minici, María Pía López, Vanina Escales, María Florencia Alcaraz, Verónica Gago, Sabrina Cartabia, Mariana Carbajal, Marina Mariasch, Jazmín Risé, Virginia Giannoni, Ximena Espeche y Marcela Fuentes. Ver: $\quad$ https://www.facebook.com/pg/Ni-una-menos351635908360931/about/?ref=page internal

${ }^{5}$ En la localidad de Rufino, al sur de la provincia de Santa Fe, Chiara Páez, una adolescente de 14 años, que era buscada desde el domingo 3 de mayo, apareció enterrada en la casa del novio de 16, quien confesó el crimen y fue detenido. Más información sobre el caso en agencia de noticias nacional: http://www.telam.com.ar/notas/201505/104789-chiara-paez-fiscal-novioconfesion.html. Recuperada: 22.06.2015.

${ }^{6}$ El 17 de mayo de ese año, la cuenta oficial de Twitter@NiUnaMenos tenía 8 mil seguidores y produjo unos 760 tuits desde su apertura. Durante los días de la convocatoria se generaron 958 mil menciones con el hashtag \#NiUnaMenos, alcanzando posición de trendingtopic nacional y mundial. En Facebook, a principios de junio, la cuenta de \# NUM, registraba más de 130 mil me gusta. 
que ya estaba instalada y recorría como un susurro los dispositivos virtuales de comunicación, en pocas horas se alcanzó un momento de condensación, provocando la circulación de una gran cantidad de imágenes, compuestas, principalmente por ilustraciones que incluían el hashtag \#NiUnaMenos y la referencia a marchar el "3 de junio a las 17 horas", en más de sesenta ciudades argentinas. ${ }^{7}$

Las movilizaciones de mujeres en el país cuentan con un antecedente insoslayable que se repite y amplía año tras año desde 1986, con cada Encuentro Nacional de Mujeres. Estas reuniones multitudinarias marcan el ritmo creciente del movimiento, ejercitando su progresiva radicalidad, capacidad de organización y unidad en las posiciones que más impugnan las consecuencias nefastas del sistema patriarcal y neoconservador en el presente (Masson, 2007). ${ }^{8}$

La creciente masividad de estos acontecimientos tiñe de violeta y magenta las calles de las principales ciudades del país durante las fechas marcadas en un calendario consolidado a nivel mundial: 8 de marzo, Día internacional de la mujer; 28 de mayo. Día Internacional de Acción por la Salud de las Mujeres, Derechos Sexuales, Derechos Reproductivos; 23 de septiembre, Día Internacional contra la Explotación Sexual y la Trata de Personas; 28 de septiembre, Día por la Despenalización del aborto en América Latina y el Caribe; 25 de noviembre, Día contra la violencia de género, para mencionar los más convocantes.

\footnotetext{
7 Para María Pía López (2015), "si esto cuajó es porque había algo que lo pre existía, una conjunción entre ánimo social y trabajo minucioso de los grupos activistas que venían, con empecinamiento necesario, aunque tantas veces desoído, tratando de llamar la atención sobre la cuestión" (s/p).

8 La noción de Patriarcado es una de las categorías centrales de la historia de la teoría feminista, y como tal, no está ausente de controversias. Amén de las críticas legítimas y pertinentes al modo que este concepto ha sido utilizado por algunas vertientes del feminismo, el mismo sigue siendo útil porque ha logrado instalar que las relaciones de poder entre los sexos responden a un sistema de organización social que, más allá de las variantes en función del contexto histórico y cultural, se mantiene vigente reproduciendo las desigualdades de poder (Fabbri, 2013).
} 
Todas estas instancias de participación, activismo, involucramiento corporal y agencia, donde se entrecruzan las corrientes de la militancia partidaria y de organizaciones sociales, así como expresiones autónomas o las jóvenes formaciones denominadas "colectivas feministas" han hecho crecer de a miles cada nuevo acontecimiento, donde el problema de las violencias sexistas es un tema central, aunque no el único.

En un proceso continuo de potenciación urgente, las multitudinarias marchas de \#Ni Una Menos de los días 3 de junio de 2015 y de $2016^{9}$, la inmensa convocatoria del último Encuentro Nacional de Mujeres $^{10}$, celebrado en la ciudad de Rosario, la jornada de Paro de Mujeres del 19 de octubre de ese mismo año, y el Paro Internacional de Mujeres, realizado el 8 de marzo de 2017, ponen en escena la persistencia de estas luchas, así como la irreverencia y la creatividad del movimiento feminista en el país para visibilizar sus reivindicaciones y demandas urgentes para acabar con este fenómeno que no cesa de crecer y recrudecerse.

El último jueves de abril de 2017, mientras la noticia de la aparición sin vida de la joven Araceli Fulles sacude Argentina, por las redes circula a gran velocidad un mapa temporal que recopila de forma minuciosa los hechos de violencia machista producidos en tan solo un mes. La impactante imagen del calendario activa una nueva ola de indignación colectiva y su correspondiente correlato viral, llegando a todos los timeline y grupos de whatsapp en pocas horas. El registro posee una gran contundencia visual, ubicando fechas, nombres de las víctimas y códigos de color para identificar distintos hechos o formas de violencia machista: el verde indica "desaparecida", el fucsia "asesinada", el rojo "asesinada y abusada" y el negro, "abusada".

\footnotetext{
9 La campaña \#Ni Una Menos es el resultado de la reacción construida al calor de la indignación colectiva producida por un nuevo y brutal femicidio que se suma a la lista de asesinatos provocados por la violencia machista. La iniciativa congrega centenares de miles de personas en marchas y actos en todo el país.

${ }^{10}$ En el $31^{\circ}$ ENM participaron más de 70.000 mujeres provenientes de todos los rincones del país de y países de la región. Para más información sobre la edición número 31 del ENM ver: http://encuentrodemujeres.com.ar/.
} 
El mapa temporal sintetiza la crueldad de una estadística, desnudando el incremento feroz de la violencia sistemática contra las mujeres en el país, entendida aquí como pedagogía disciplinadora y restauradora del orden patriarcal (Segato, 2014). Sin embargo, esta imagen, así como la magnitud de su circulación, nos permite reconocer que las estrategias de visibilización y viralización configuran la trama de acción política de las resistencias feministas contemporáneas, su capacidad de disputas de sentidos y su carácter contrahegemónico.

Figura 1: Mapa temporal Violencia de Género.

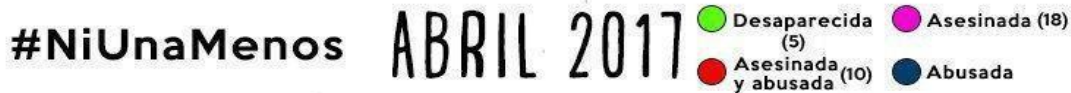

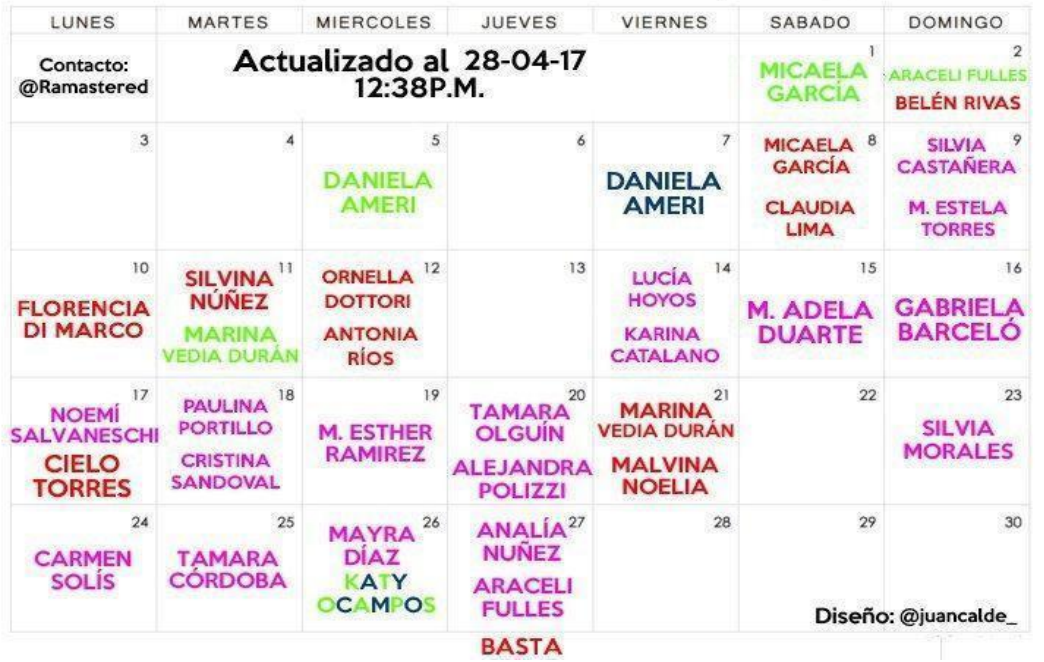

Fuente: @Ramastered

En la capacidad de construir agenda de un movimiento heterogéneo, amplio y, a la vez, organizado, el uso de las tecnologías infocomunicacionales son apuestas cada vez más creativas, sutiles y certeras dirigidas a subvertir las 
representaciones mediáticas de las violencias sexistas, ancladas en la repetición de imaginarios victimizantes ${ }^{11}$.

\section{Las iconográficas se transforman velozmente}

En apenas dos años transcurridos desde la campaña iniciada por \#NUM, invitando a marchar el 3 de junio de 2015 y el presente en el que escribimos este artículo (junio de 2017), han proliferado los espacios virtuales impulsados por organizaciones de mujeres, colectivas y activistas que desde todos los rincones del territorio nacional suman voces y miradas a la corriente de producción visual con nuevos eventos, fanpage, páginas y posteos circulantes.

Y en este breve lapso de tiempo las iconografías se han modificado sustantivamente. tal como lo hemos advertido en análisis precedentes (Rovetto y Camusso, 2015; 2017). De ahí se sostiene que las prácticas de visibilización despliegan estrategias de acción inéditas cada vez más creativas y masivas, complejizando y ampliando los sentidos que buscan denunciar la desigualdad histórica de las mujeres en la sociedad y sus múltiples consecuencias. Ya no se trata solo de hacer audible "Basta de Femicidios" en las redes y en las calles, sino de ampliar contagiosamente los modos de representación para promover transformaciones radicales en los modos del vivir. Esto se evidencia en la incorporación definitiva de iVIVAS NOS QUEREMOS! a las imágenes producidas en el marco de cada nueva movilización.

Ejemplos de este desplazamiento de sentidos acompañaron la jornada del Paro Internacional de Mujeres del \#8M: \#Ni Una Menos; \#Vivas Nos Queremos; \#Toda Lucha de las Mujeres es

${ }^{11}$ En la capacidad de producción y circulación de propuestas iconográficas, las mujeres jóvenes han tenido un rol fundamental. Al respecto, Laudano (2016) señala que las "colectivas" jóvenes se destacan por una relación fluida con plataformas infocomunicacionales como FB que, a su vez, configuran de manera singular sus prácticas activistas y constituyen un cambio significativo respecto a las de los grupos feministas en décadas anteriores. 
Lucha Feminista; \#Trabajadoras Somos Todas; \#Estamos Para Nosotras; \#Aborto Legal Seguro y Gratuito; \#Si nuestras vidas no valen, iproduzcan sin nosotras!; \#Basta de Violencia a las Cuerpas Disidentes; \#Nosotras nos Organizamos; \#El Estado es Responsable de la Violencia contra las Mujeres; \#Nos Mueve El Deseo;\#Hacemos que la Tierra Tiemble...

Los sintagmas danzan en las redes, rítmicamente, junto con imágenes fijas, en movimiento y sonidos. Son replicadas individual y colectivamente alentando acciones colectivas de denuncia, movilización, encuentro, toma de conciencia que se entrelazan con nuevos lenguajes, formas y representaciones. La indignación que motivó aquel primer 3 de junio de 2015, da paso gradual y paulatinamente, a la producción de nuevos sentidos que impactan en los "modos del decir y del hacer" antes, durante y después de cada nueva convocatoria: 3 de junio de 2016, 19 de octubre de 2016, 25 de noviembre de 2016, 8 de marzo de 2017, tiñen de magenta en el calendario virtual, ampliando el horizonte de lo pensable, ya no sólo de las violencias sexistas, sino la vida que queremos vivir.

En este marco, tampoco que casual que los tuits sobre el "feminismo" o los "derechos de la mujer" (y las traducciones de esas frases en diez idiomas) se incrementan progresivamente respecto al año 2015, y que los hashtags \#NiUnaMenos y \#VivasNosQueremos fueron las mayores tendencias en América Latina, según informa Twitter $^{12}$.

\footnotetext{
${ }^{12}$ En 2016, hubo un $25 \%$ más de tuits sobre el "feminismo" o "derechos de la mujer" que, en 2015, mientras que hasta ahora en 2017, la conversación se duplicó respecto al mismo período del año pasado", informó la red social en un comunicado. Además, Twitter resaltó que la participación de las mujeres y la igualdad en la fuerza laboral fue una de las principales conversaciones en la plataforma en 2017. Más información disponible en: http://www.telam.com.ar/notas/201703/181862-aumento-tuits-feminismoderechos-de-la-mujer.html.
} 


\subsection{Imaginar lo imaginable: nuevas visualizaciones}

En este tiempo, breve pero profuso en acciones políticas y comunicacionales, advertimos que las prácticas de visibilización del fenómeno de las violencias sexistas se ha complejizado en consignas y convocatorias circulantes en las redes y en las calles. Como consecuencia de esta emergencia de consignas y activismo, con prácticas cada vez más creativas y medidas de fuerza inéditas, comienzan a circular nuevos sentidos que buscan denunciar la desigualdad histórica de las mujeres en la sociedad y sus múltiples consecuencias. Así, tanto las violencias machistas -y su expresión más extrema, los femicidios- como las muertes por abortos inseguros, pasando por el trabajo doméstico y de cuidados no remunerado, la negación del derecho al aborto o la precarización laboral encuentran su representación gráfica en las redes, y con ellas también su caja de resonancia y difusión. En este marco, las consignas se politizan radicalmente y las imágenes se vuelven más disruptivas y contundentes ${ }^{13}$.

De ahí, sostenemos que la estrategia visual de identificación del colectivo \#NUM, activo en la organización del evento a nivel local, expresa el grado de importancia que las discusiones en torno a las visualidades han generado al interior de los movimientos feministas. No parece casualidad que su identidad pública se haya construido a partir de una propuesta visual que prescinde de las representaciones figurativas como elemento principal y opta por la abstracción que ofrece el componente tipográfico (la silueta que refiere al signo mujer pictográfico dentro de una letra A). Esta abstracción que posibilita la generalización de un concepto que incluye a todas las mujeres con todas sus diversidades -difícil de realizar en representaciones icónicas sin acudir a algún modo de

${ }^{13}$ Algunas de las consignas de la convocatoria con mayor difusión en las redes sociales fueron: \#NosotrasParamos, \#EstamosParaNosotras, \#VivasNosQueremos \#NiUnaMenos, "Si nuestras vidas no valen, iproduzcan sin nosotras!, \#NosMueveEIDeseo, \#NosotrasMovemosEIMundo o "Hacemos que la Tierra Tiemble", entre otras. Cada una de ellas merecería un desarrollo analítico situado que esperamos producir próximamente. 
estereotipia- se manifiesta con una tipografía despojada y pregnante $y$ con un color -el magenta puro- que tensiona semantizaciones en torno a "lo femenino", pero las subvierte con su saturación, intensidad y dificultades combinatorias. Este color que sólo funciona señaléticamente a pleno con blanco o con negro, contribuyó a -luego de muchas deliberaciones ${ }^{14}$ - constituir un núcleo identitario contundente, que sacudió el universo de las representaciones feministas y de género.

Figura 2: Gráfica convocatoria Movilización 3 de junio 2015.

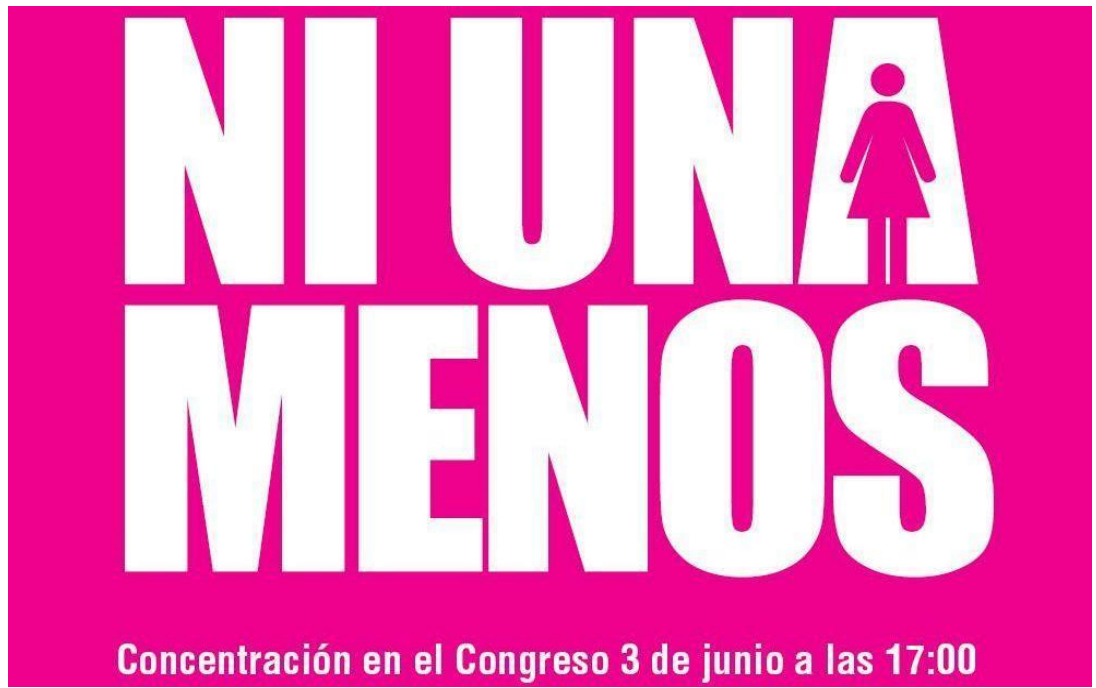

Fuente: Facebook Ni Una Menos

Es posible que esta pura posibilidad de un color, reproducida ad infinitum en marchas, redes sociales, medios masivos, carteles, volantes, pancartas, animaciones, haya posibilitado la instalación -con ribetes, con discusiones, con

\footnotetext{
${ }^{14}$ La selección del color fue un tema de discusión importante en las asambleas organizadas por el movimiento de mujeres en distintas ciudades del país. Usar el color negro, como muchas organizaciones internacionales, consolidar el violeta característico del feminismo o elegir un color particular fueron las mociones en pugna.
} 
cuestionamientos pero con indudable masividad- de cierta discursividad feminista en la agenda cotidiana, en tanto haya sido para muchas mujeres no militantes, alejadas de las discusiones políticas, pero conmovidas y movilizadas por el aumento de femicidios y de la crueldad de los mismos, un símbolo más amigable, más reproducible, más internalizable.

\subsection{Descripción y análisis de las transformaciones iconográficas}

Si la representación visual del propio colectivo de mujeres ha constituido un foco de atención para $\# N U M$, este proceso no parece ajeno a las transformaciones que se evidencian en las imágenes que son puestas en circulación constantemente por organizaciones y usuarias individuales en Facebook Al ritmo de la vertiginosidad de las redes, las imágenes se transforman cualitativamente, permitiendo vislumbrar entre sus trazos, el impacto que están teniendo las discursividades feministas sobre la cultura contemporánea.

Es notable que, aun cuando las demandas enunciadas el \#8M adquieren su propia impronta en cada país y ciudad, existe un denominador común: se trata de una respuesta a la actual violencia social, económica, legal, política, moral y simbólica. Y esa respuesta se manifiesta con intensidad en una circulantes, constituyendo un palimpsesto iconográfico que evidencia profundas transformaciones en comparación al corpus que analizamos inicialmente.

De ahí que, esta etapa de análisis y observación de iconografías producidas en el contexto de la segunda convocatoria de \#NUM (movilización del 3 de junio de 2016) y del Paro Internacional celebrado \#8 de marzo- nos permite reconocer al menos 6 transformaciones que describimos a continuación mediante ejemplos con los que identificamos las operaciones retóricas, discursivas y estilística puestas en circulación. 
Transformación 1. De las niñas dolientes a las mujeres en lucha:

La mayor parte de la imágenes que fueron muy difundidas en la primera convocatoria \#NUM (2015) y remiten a la resignación de las víctimas, la pasividad y la afectividad doliente (Rovetto y Camusso, 2015) mutan hacia representaciones más combativas, donde las mujeres otrora aniñadas pasan a ser representadas en desafiante actitud de lucha a partir de operaciones de adjunción de gestos (puños en alto, "fuckyou") o de tramas cromáticas que remiten, intertextualidad mediante, a la iconicidad de las luchas.

Vale señalar que estas transformaciones se producen por decisión de sus autorxs (figura 3 y 4) que, "al calor de las masas", reversionan las creaciones dotándolas de nuevas significaciones (intratextualidad), o por intervenciones de otrxs (figura 6), que "citan" la obra original al mismo tiempo que la transgreden (extratextualidad).

Figura 3: \#Ni una Menos por Liniers, 2015

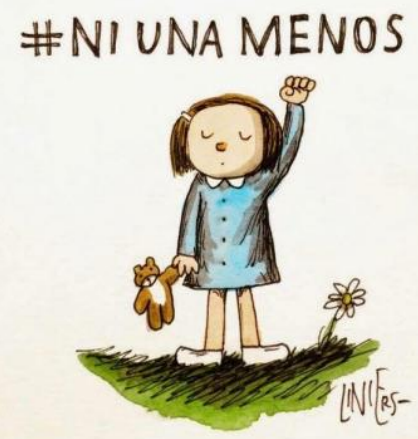

Fuente: Facebook Ni Una Menos 
Figura 4: \#Ni una Menos por Liniers, 2017

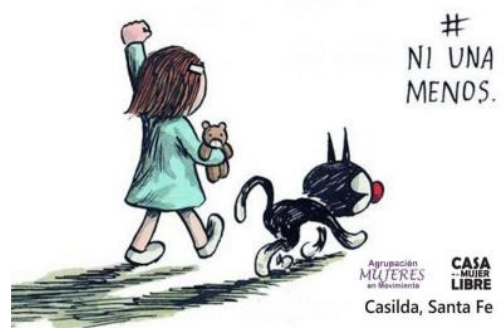

Fuente: Facebook Ni Una Menos

Figura 5: \#Ni una Menos, por Romina Lerda, 2016

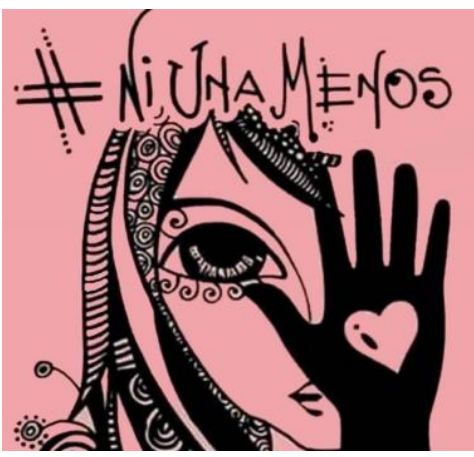

Fuente: Facebook Ni Una Menos

Figura 6: \#Ni una Menos. Anónima 2017

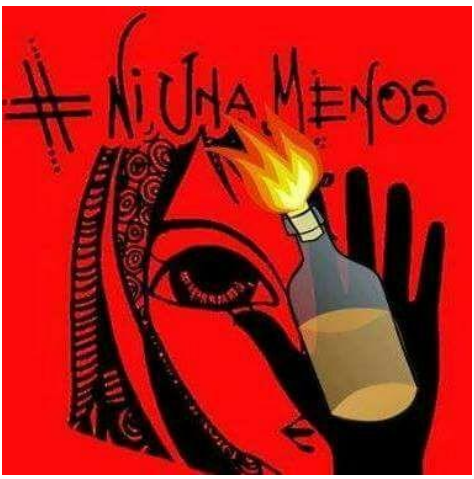

Fuente: Facebook Ni Una Menos 


\section{Transformaciones 2. De lo "femenino" a lo feminista}

Si en las primeras convocatorias -incluyendo dentro de este término tanto lo que sucedía en la calle como en las redesabundaban imágenes caracterizadas por una presencia reiterada de elementos que aluden a la estereotipia de "lo femenino" (Rovetto y Camusso, 2015), en las movilizaciones más recientes encontramos que estos atributos -flores, arabescos, mariposas- se fusionan con símbolos provenientes del activismo político, como marchas, pancartas.

Así, la adjunción genera imágenes que se inscriben en una genealogía visual que no abjura de sus significantes, pero los resemantiza cargándose de activismo contestatario (figuras 7 y 8).

Figura 7: Imagen de Miguel Pinto

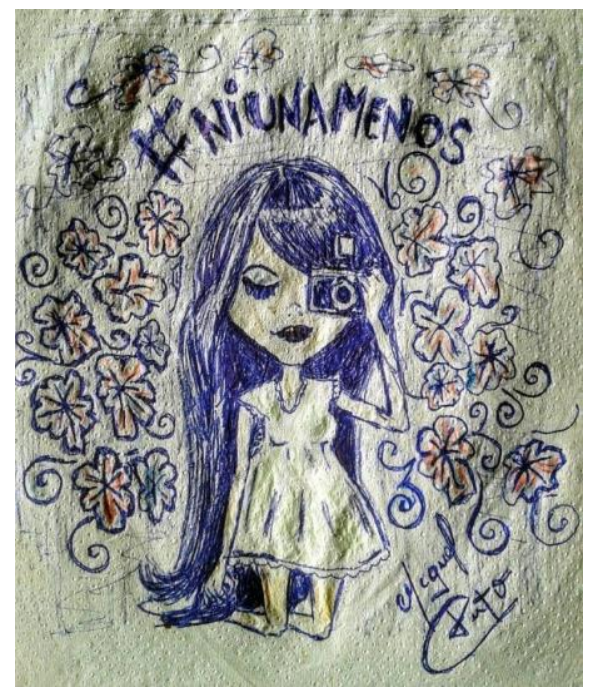

Fuente: Facebook Ni Una Menos 
Figura 8: Imagen promocional de la película "Cada 30 horas" de Alejandro Perdomo, reutilizada en posteos publicados en Facebook

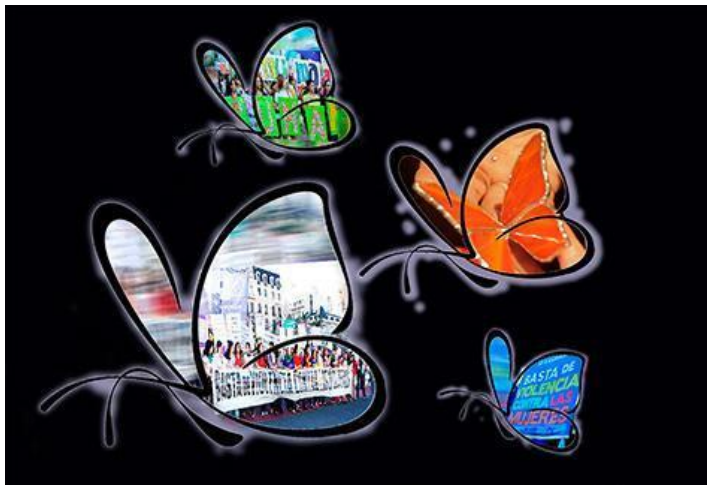

Fuente: Facebook Ni Una Menos

Transformación 3. De la víctima solitaria al colectivo de mujeres

La soledad de la víctima -representada por mujeres pequeñas en relación al espacio ocupado, por la ausencia de otras personas en las ilustraciones, pero también de referencias contextuales; simbolizada por dibujos de mujeres aniñadas, de cuerpos inermes, de colores fríos y desaturados- fue una constante en la primera etapa del movimiento, que contrastaba con campañas de otros países, como la arquetípica \#Vivas nos queremos de México (Rovetto; Camusso, 2015)

Esas mujeres, solas y aisladas, se sustituyen gradualmente por imágenes de grupos de mujeres que además son representadas -o se representan a sí mismas- en acciones colectivas: y cuyos rasgos dan cuenta de una intencionalidad de diversificación de las representaciones: diferentes edades, diferentes cuerpos, diferentes vestimentas (figuras 9 y 10). 
Figura 9: Ilustración de Marchese. (2016)

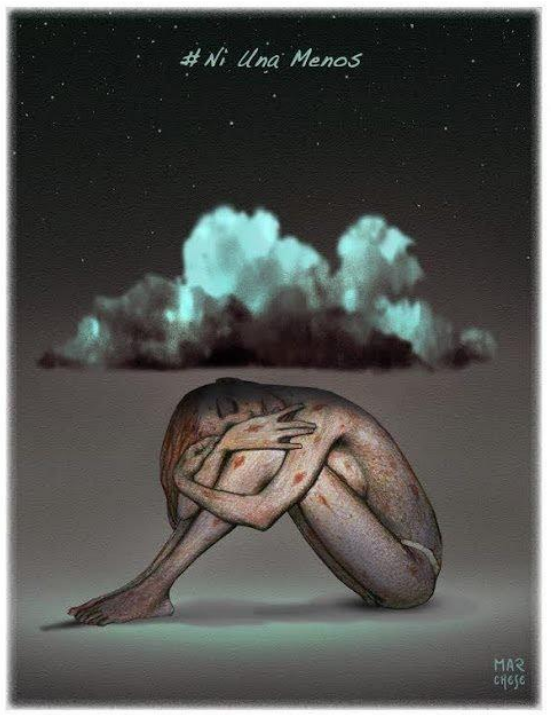

Fuente: Facebook Ni Una Menos

Figura 10: Imagen anónima. (2017)

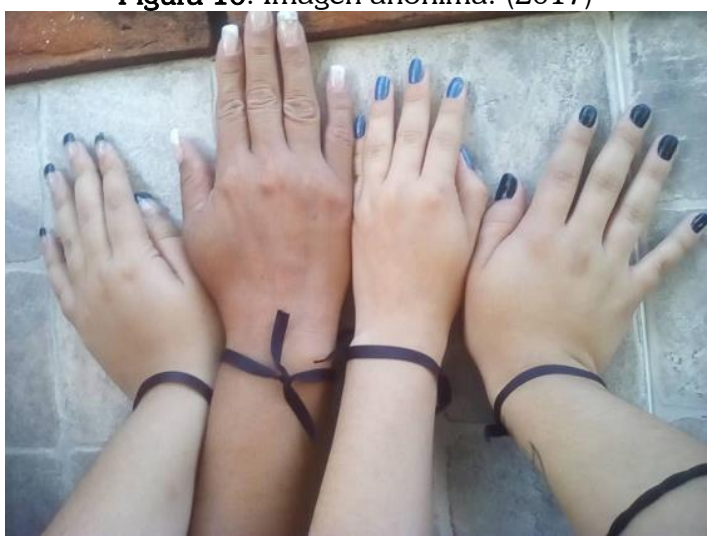

Fuente: Facebook Ni Una Menos 


\section{Transformación 4. De la "Pitufina" a la genealogía de las mujeres en lucha}

Las imágenes generadas por mujeres con técnicas y recursos amateurs, para ser compartidas y replicadas en las redes, dan cuenta de un doble proceso: por un lado, cada imagen implica una inscripción de la experiencia personal en las luchas feministas, por otro, inscribe esa adhesión en una genealogía política leída en clave de género.

Así, encontramos fotografías que participan de movidas virales, como el uso de la cinta negra junto con la referencia a las identificaciones políticas de quienes las producen: cinta negra y foto de Eva; cinta negra e imagen de Milagro Sala; cinta negra y pañuelo verde de la campaña por la despenalización del aborto. Todas estas imágenes aluden simbólicamente a un rasgo distintivo del movimiento de mujeres donde converge una causa común y las reivindicaciones específicas con procedencias y recorridos diversos.

Este juego de citas y adhesiones propone desarticular el síndrome de "Pitufina ${ }^{15}$. desacralizando a esas mujeres excepcionales que funcionaban, a la vez, como ideal inalcanzable (figura 11), reinscribiéndolas en el territorio de las luchas feministas. Sitúan el fenómeno particular \#NUMen la larga historia de las luchas del movimiento mujeres con la materialización visual de uno de los axiomas básico del feminismo: "lo personal es político" (figura 12).

\footnotetext{
${ }^{15}$ El Síndrome de Pitufina permite comprender las representaciones de mujeres que las sitúan en un plano de excepción. Hay algo en esas mujeres que las ha hecho capaces de destacarse en un mundo habitualmente dominado por los hombres, su llegada a espacios de poder es individual y desembragada de la militancia colectiva con perspectiva de género. Con esta noción, la socióloga canadiense, Anita Sarkeesian, revisa la construcción de personajes femeninos y masculinos en películas, juegos o dibujos animados. Para más información ver: http://www.youtube.com/watch?v=opM3T2 IZA.
} 
cadernos pagu (58), 2020:e205816

Florencia Laura Rovetto

Mariaángeles Camusso

Figura 11: Mujeres "incomparables" en perfiles de Facebook de grupos de sindicatos, partidos políticos o áreas del Estado (Rovetto, Camusso, 2013).

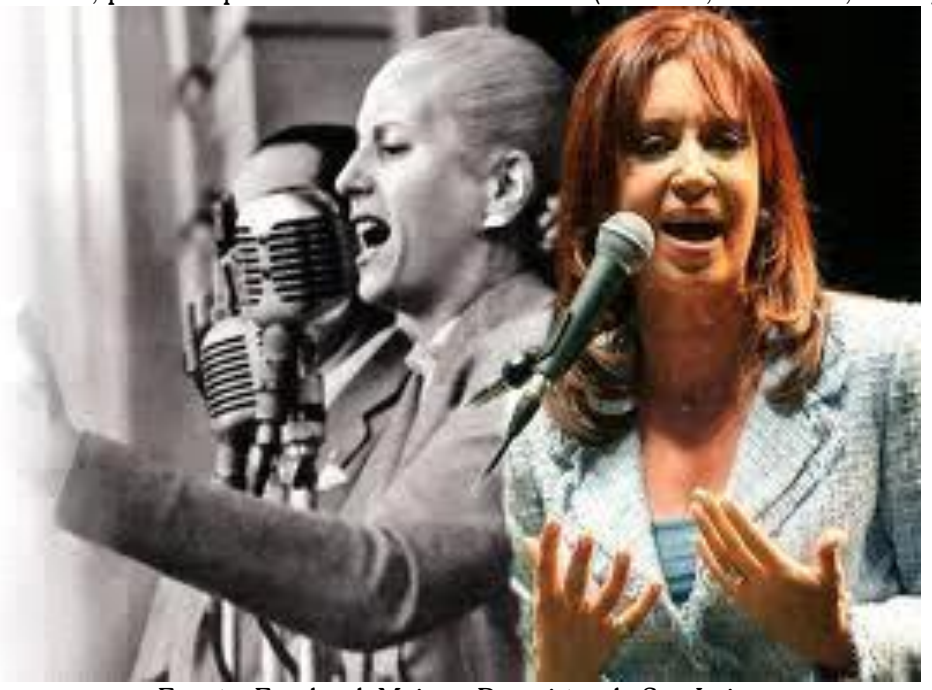

Fuente: Facebook Mujeres Peronistas de San Luis.

Figura 12: Collage realizado a partir de imágenes compartidas a finales de 2016.

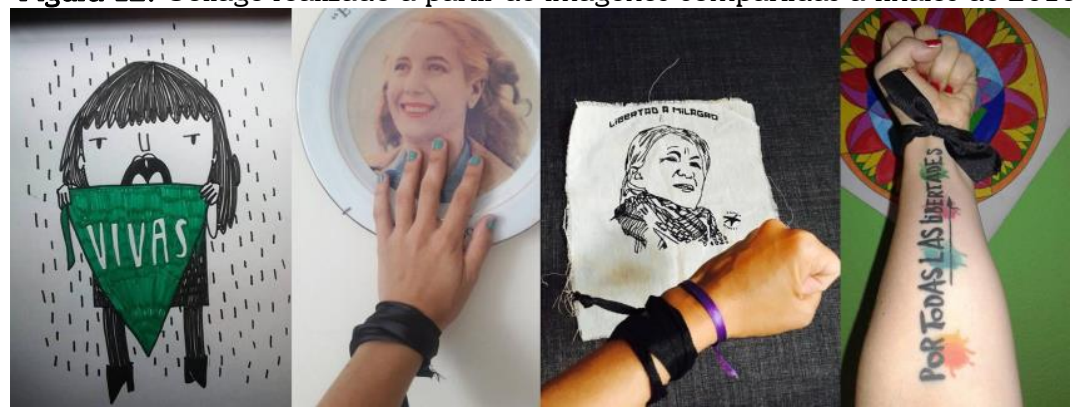

Fuente: Facebook Ni Una Menos. Collage elaboración propia 
Transformación 5. De la estereotipia de "la mujer" a la diversidad de las mujeres

El recorrido que venimos haciendo en torno a las modalidades de representación de la mujer víctima, la mujer sola, la mujer aniñada, la mujer política, se inscribe en un problema de orden semiótico: la dificultad o imposibilidad que tienen las imágenes para representar conceptos abstractos sin utilizar estereotipos. Cuando decimos, leemos, escribimos la palabra "mujer" desarrollamos una imagen mental propia, que puede parecerse más o menos a la imagen mental de otrxs sujetos. Las imágenes materiales, adolecen de esa posibilidad: cada imagen implica una selección concreta de rasgos que al cristalizarse en un signo visual que, en este proceso, configura determinados modos de representar en detrimento de otros.

Esta dificultad para representar conceptos generales -la mujer, en este caso- se salda con la utilización de ciertos caracteres que, en determinado momento y determinado lugar, se constituyeron convencionalmente como los rasgos distintivos del término. El pelo largo, los vestidos, los ojos grandes y con pestañas arqueadas, las bocas carnosas son algunos de los elementos reiterados en las representaciones canónicas de las mujeres en las imágenes circulantes durante el primer \#NUM (figura 13).

Figura 13: Collage realizado a partir de imágenes compartidas en días previos a la marcha del 3 de junio de 2015

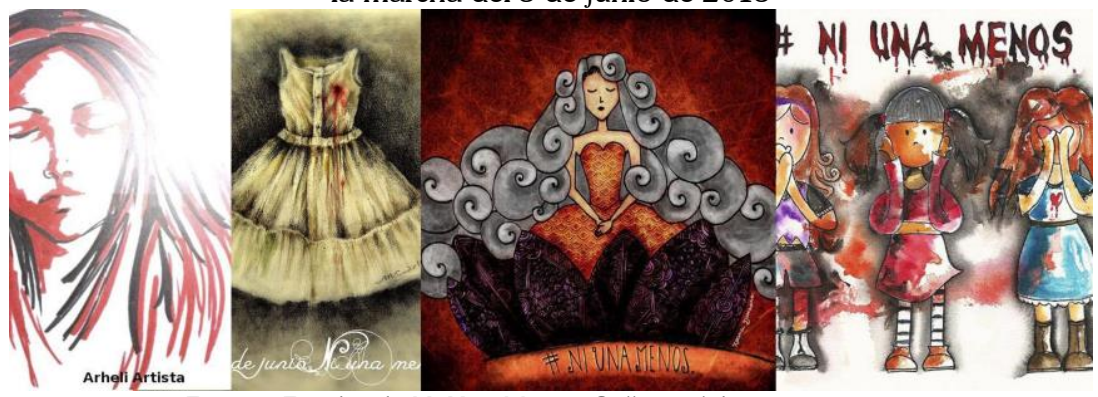

Fuente: Facebook Ni Una Menos. Collage elaboración propia. 
Por el contrario, las imágenes de mujeres analizadas en las posteriores movilizaciones manifiestan paulatinamente una creciente diversificación, abriendo el juego a la pluralidad de representaciones visuales. Imágenes que no responden a cánones estéticos hegemónicos; referencias a otros colectivos invisibilizados, marginalizados o violentados; incorporación de imágenes de mujeres de diferentes edades, razas y grupos sociales, dan cuenta de la necesidad de romper con los estereotipos que, lejos de representar a grupos amplios de mujeres, no logran generar identificación con alguna (figura 14).

Figura 14: Collage realizado a partir de imágenes compartidas en días previos al paro de mujeres del 19 de octubre de 2016.

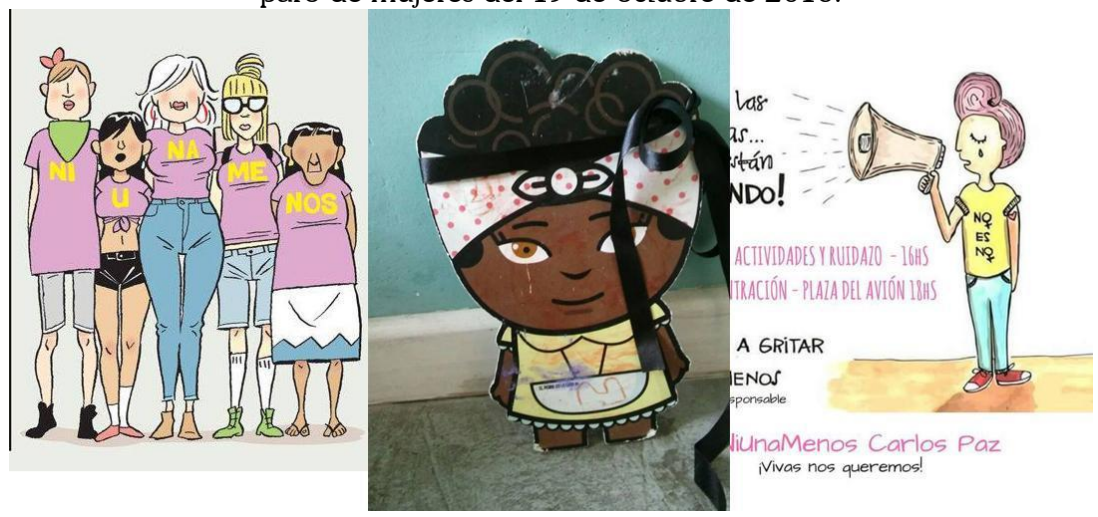

Fuente: Facebook Ni Una Menos. Collage elaboración propia.

\section{Transformación 6. Del entorno fantástico a la inscripción en lo cotidiano}

Si en el análisis de imágenes de la primer marcha \#NUM, habíamos señalado que la violencia de género era representada como una monstruosidad o excepción terrorífica, desde 2016 en adelante estas formas de violencias sexistas comienzan a representarse como estructurantes de la vida social en el sistema patriarcal: los paisajes fantásticos (bosques, arboledas) son sustituidos por contextos cotidianos en los que los significantes asociados al machismo colisionan con los vinculados a la lucha 
feminista que confronta el sentido de la excepcionalidad, entre otros.

Una acción notable, al respecto, fue la inclusión de mensajes en billetes de curso legal, que permitió, en un mismo procedimiento, hacer visible la internacionalidad de los reclamos y aludir, metonimia mediante, al frente capitalista-patriarcal como sistema político-económico de opresión que las feministas ponen en agenda.

Figura 15: Imagen de Luciana Feito, compartida en días previos a la primera movilización del 3 de junio de 2015.

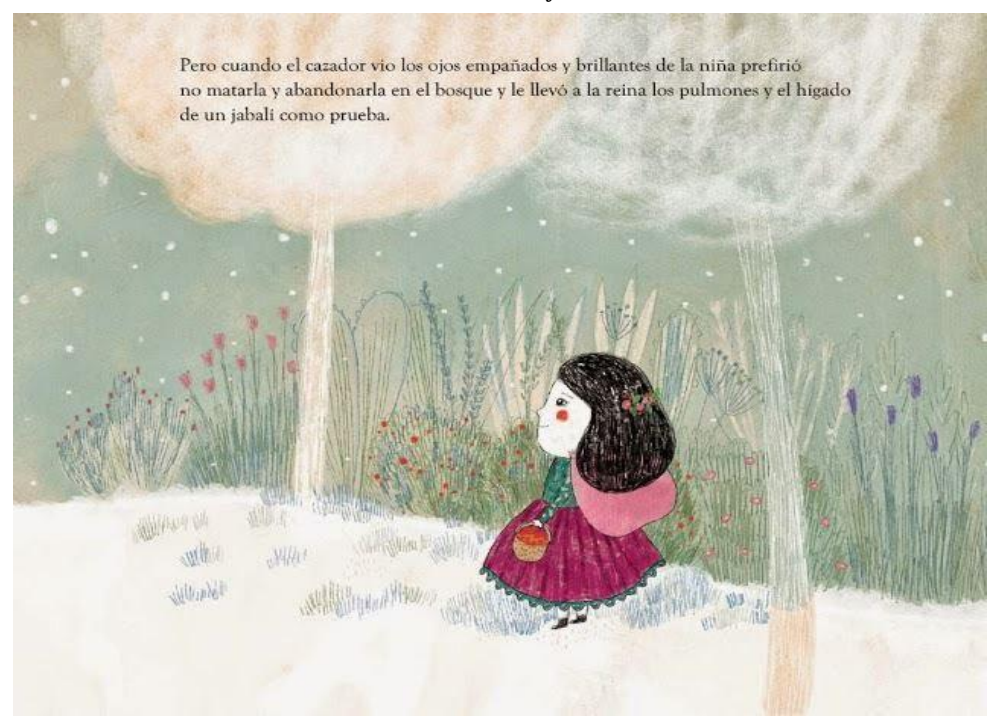

Fuente: Facebook Ni Una Menos 
cadernos pagu (58), 2020:e205816

Florencia Laura Rovetto

Mariaángeles Camusso

Figura 16: Imagen que promovía el utilizar billetes como soporte de difusión del Paro Internacional de Mujeres convocado para el 8 de marzo de 2017.

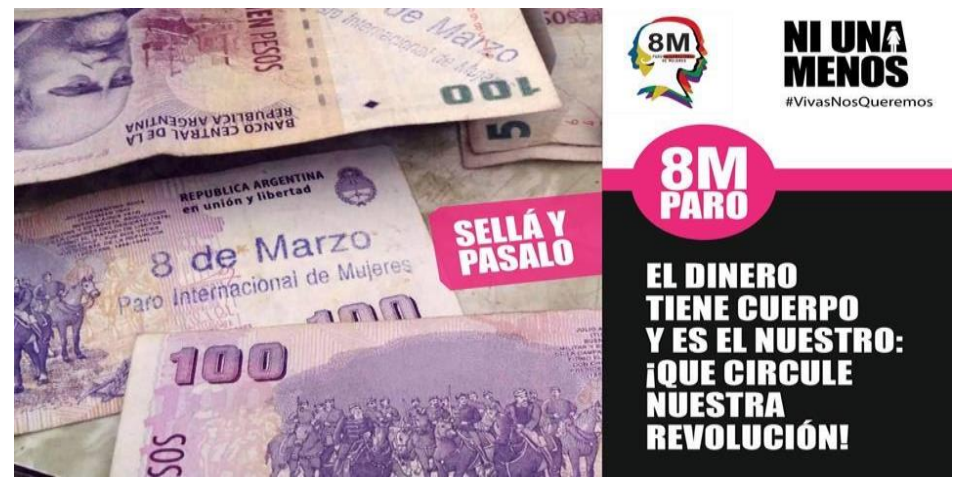

Fuente: Facebook Ni Una Menos

Figura 17: Collage de imágenes compartidas en Facebook Ni Una Menos los días previos al Paro Internacional de Mujeres \#8M.

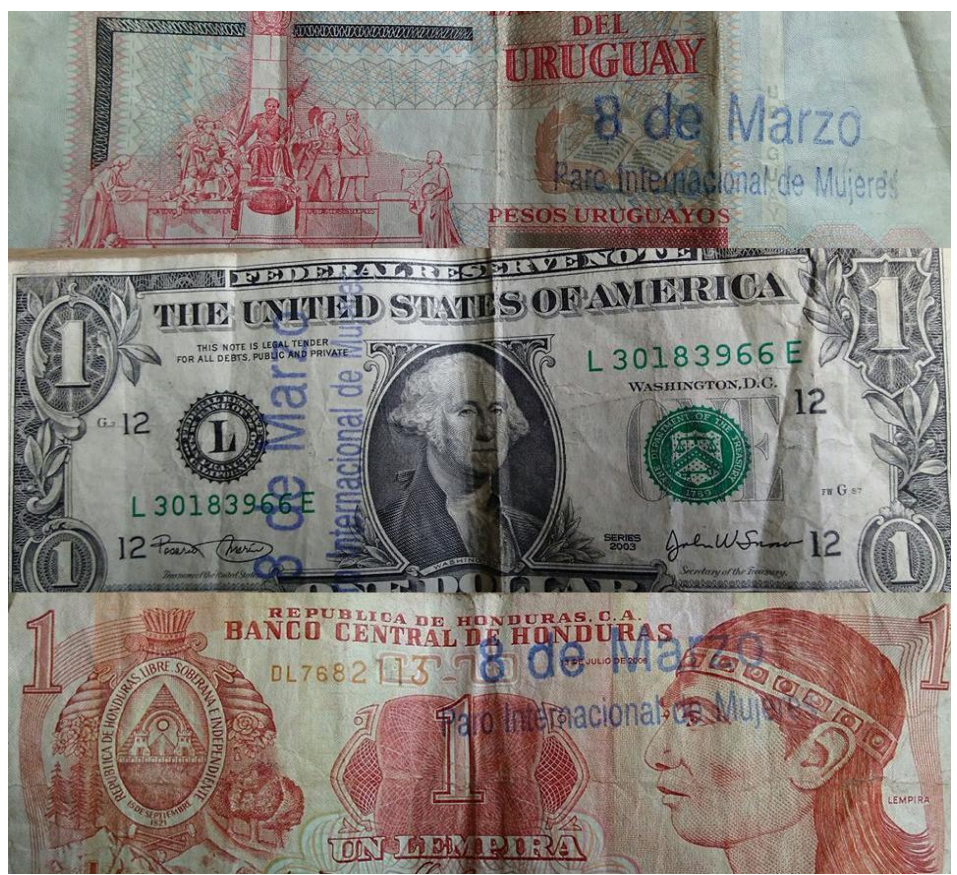

Fuente: Facebook Ni Una Menos. Collage elaboración propia. 


\section{Consideraciones finales}

En este trabajo problematizamos sobre los modos producción iconográfica que adquieren visibilidad y circulación a través de la plataforma infocomunicacional de Facebook, en el actual proceso de expansión de las luchas feministas. Para ello, hemos recorrido los acontecimientos más significativos que, desde la irrupción en el espacio público del fenómeno \#NUM, reconfiguran las formas de visibilidad y de acción política del movimiento de mujeres y feministas en el país, transformando las imágenes, las maneras de mostrar y decir.

A partir del análisis de ejemplos concretos hemos expuesto los contrastes disrupciones y continuidades en un corpus de imágenes extraídas de Facebook durante un periodo corto pero intenso en producción y circulación iconográfica sobre la problemática de la violencia sexista. Con ellos hemos podido identificar, también, las operaciones retóricas, discursivas y estilísticas circulantes en el espacio público, donde las redes sociales pueden ser leídas como un campo fértil para el despliegue de luchas significantes.

Finalmente, destacamos la exaltación creciente de la performatividad en las numerosas manifestaciones callejeras convocadas entre 2015 y la actualidad, no tanto como una transformación, sino como un ejercicio que amplifica el repertorio de una genealogía performática del movimiento feminista, así como de las experiencias queers que encuentran en la circulación digital nuevas formas expresivas.

En este sentido, la multiplicidad imágenes, memes, posteos, dan cuenta de procesos dinámicos, pero también controversiales, en tanto las identidades digitales de lxs sujetxs que publican o replican no necesariamente dan cuenta de algo que podríamos llamar "conciencia feminista", entendiendo esta como una sólida y fundamentada forma de interpretar el actual estado de cosas $e$ impugnar las relaciones de opresión sexogenéricas. Por el contrario, lo que parecieran habilitar las redes es la posibilidad de ciertos agenciamientos a través de los cuales "la propia historia es 
interpretada o reconstruida por cada una de nosotras dentro del horizonte de significados y conocimientos disponibles en la cultura en un momento dado, un horizonte que también incluye formas de compromiso y lucha política" (De Luretis 1986, en Elizalde, 2008). Siguiendo a estas autoras podemos pensar que las prácticas de producción significante a través de los usos colectivos de las redes hacen visible y observable justamente la experiencia cotidiana de las mujeres como locus de una agencia resistente a los sistemas de significación abstractos, sustraídos de sus experiencias vitales, así como a las regulaciones hegemónicas de sentidos (Elizalde, 2008).

Concluimos que el repertorio iconográfico analizado corre los límites de lo decible y lo mostrable, visibilizando el accionar del movimiento feministas contemporáneo, que con su voluntad político-pedagógica y su capacidad de resignificación constante va ampliando el horizonte de las transformaciones por venir ya no sólo para eliminar el flagelo de las violencias sexistas, sino para imaginar la vida que queremos vivir.

\section{Referências bibliográficas}

BACHElard, Gaston. The Poetics of Space. New York, Orion, 2016 (1964).

CAgGiano, Sergio. El sentido común visual. Disputas en torno a género, "raza" y clase en imágenes de circulación pública, Buenos Aires: Miño y Dávila, 2012.

CAlabrese, Omar. ¿Cómo se lee una obra de arte? Madrid, Cátedra, 1999.

De Lauretis, Teressa. Alicia ya no. Feminismo, semiótica, cine. Madrid, Cátedra, 1992 (1984).

DE LAuRETIS, Teressa. Feminist Studies-/Critical Studies. Indiana University Press, Bloomington, 1986.

ELIZALDE, Silvia. Debates sobre la experiencia. Un recorrido por la teoría y la praxis feminista. Oficios Terrestres, La Plata, Facultad de Periodismo y Comunicación Social, 2008, pp. 18-30. 
FABBRI, Luciano. Apuntes sobre feminismos y construcción de poder popular. Rosario, Puño y Letra, 2013.

LAUDANO, Claudia. Feministas en la red. Reflexiones en torno a las potencialidades y restricciones de la participación en el ciberespacio. In ROVETTO, Florencia y FABBRI, Luciano (ed.) Sin feminismos no hay democracia. Rosario, Último recurso, 2016, pp. 31-54.

LÓPEZ, María Pía. Ni una menos: aquelarre y algarabía. Página 12. Buenos Aires, 2015, [http://www.pagina12.com.ar/diario/sociedad/3273992-2015-06-02.html acceso el 29 de junio de 2016].

MASSON, Laura. Feministas en todas partes. Una etnografía de espacios y narrativas feministas en Argentina. Buenos Aires, Prometeo, 2007.

ROVETTO, Florencia; CAMUSSO, Mariángeles. Representaciones iconográficas feministas, de mujeres y de género en las redes sociales. In RovetTo, Florencia y Reviglio, Cecilia (ed.). Estado actual de las investigaciones sobre mediatizaciones. Rosario, UNR Editora, 2014, pp. 77-94.

RovetTO, Florencia y CAMUSSO, Mariángeles. "\#Ni una (imagen) menos. Imágenes, apropiaciones y circulación en las redes sociales". En CiNGOLANI, Gastón y SZNAIDER, Beatriz (ed.) Nuevas mediatizaciones y nuevos públicos: cambios en las prácticas sociales a partir de las transformaciones del arte y los medios en la red, Rosario. UNR Editora, 2015, pp. 159-177.

RovetTo, Florencia y CAMUSSO, Mariángeles. Naturaleza y artificio: Iconografías de mujeres políticas en la bisagra de un "cambio de ciclo". In CAMUSSO, Mariángeles y BuSSO, Mariana (ed.). Mediatizaciones en tensión: el atravesamiento de lo público. Rosario, UNR Editora, 2017, pp. 86-106.

SEGATO, Rita. Las nuevas formas de la guerra y el cuerpo de las mujeres. Revista Sociedade e Estado (29), Brasilia, Departamento de Sociologia da Universidade de Brasilia, 2014, pp. 341-371.

TAYLOR, Diana y FUENTES, Marcela. Estudios avanzados de performance. México, Fondo de Cultura Económica, 2011.

Verón, Eliseo. La semiosis social. Fragmentos de una teoría de la discursividad. Buenos Aires, Gedisa, 1987. 